\title{
Testing the Performance of Some Competition Indices against Experimental Data and Outputs of Spatially Explicit Simulation Models
}

\author{
Vladimir Shanin ${ }^{1,2, *(\mathbb{D})}$, Hannu Hökkä ${ }^{3}$ and Pavel Grabarnik ${ }^{1}$ (D) \\ 1 Institute of Physicochemical and Biological Problems in Soil Science, Pushchino Scientific Center for Biological \\ Research of the Russian Academy of Sciences, 142290 Pushchino, Russia; pavel.grabarnik@gmail.com \\ 2 Center for Forest Ecology and Productivity of the Russian Academy of Sciences, 117997 Moscow, Russia \\ 3 Natural Resources Institute (LUKE), 00790 Helsinki, Finland; hannu.hokka@luke.fi \\ * Correspondence: shaninvn@gmail.com
}

Citation: Shanin, V.; Hökkä, H.;

Grabarnik, P. Testing the Performance of Some Competition Indices against Experimental Data and Outputs of Spatially Explicit Simulation Models. Forests 2021, 12, 1415. https:// doi.org/10.3390/f12101415

Academic Editor: Rafał Podlaski

Received: 16 September 2021

Accepted: 12 October 2021

Published: 16 October 2021

Publisher's Note: MDPI stays neutral with regard to jurisdictional claims in published maps and institutional affiliations.

Copyright: (C) 2021 by the authors. Licensee MDPI, Basel, Switzerland. This article is an open access article distributed under the terms and conditions of the Creative Commons Attribution (CC BY) license (https:// creativecommons.org/licenses/by/ $4.0 /)$.
Abstract: Three competition indices were tested against experimental data on the growth of individual trees in mapped forest stands and outputs of spatially explicit, process-based models of competition. The comparison showed the fundamental importance of taking into account the spatial structure of stands and, particularly, the relative spatial locations of individual trees (spatial asymmetry) when calculating the competition between trees. Although none of the competition indices are able to take into account the specific processes affecting the development of individual trees, these indices can be used in forest dynamics modeling as a simplified representation of competition between trees for resources.

Keywords: competition indices; spatial asymmetry; spatially explicit models; process-based models; boreal forest stands

\section{Introduction}

The spatial structure of natural forest stands is usually complicated and defined by the location of individual trees, their size, and species-specific peculiarities. The dynamics of the spatial structure is driven by both external (various disturbances, including management) and internal (growth of trees, regeneration, competition-induced, and natural mortality) factors. It is a common view that local interactions among individuals are a substantial factor for the formation of plant communities [1], and the quantitative estimation of such interactions continues to be one of the most important research questions [2,3]. Important features of competition that need to be accounted for in the forest ecosystem models are species-specific strategies in the development of above- and belowground organs. Additionally, the plasticity of crowns and root systems in response to competitive pressure from other individuals and heterogeneity of resources should be simulated with such models. These features result in a complex pattern of interactions in plant communities, which affect the sustainability and efficiency of the use of resources [4].

In order to estimate the between-tree competition, a large number of competition models were developed, from very simplistic ones to spatially explicit multi-dimensional mechanistic models [5-7]. Along with the mechanistic models of competition in plant communities, the simple and common approach is the use of competition indices as proxies for the intensity and direction of interactions between individual plants [8]. These indices aim to quantify the resource availability for individual trees taking into account the interactions between trees. The importance of assessment of competition tension is related to the necessity of correct estimation of the mortality rate of trees due to self-thinning. The competition indices are built on the basis of morphometric features of trees and are usually functions of distance to the closest neighbor trees and their characteristics. Later, the spatial structure of stands was also taken into account using the angular approach to assess the 
influence of neighbor trees [9]. Alternatively, an approach based on the estimation of overlap of influence zones has been proposed [10]. The competition indices are widely used due to their simplicity, in comparison to more detailed spatially explicit mechanistic models of competition based on the description of processes underlying the development of tree crowns and root systems and resource acquisition, which are thus capable to take into account the effect of spatial locations of trees on the strength of interactions between them [11,12]. Such models usually have a complex structure and a higher number of parameters, and therefore demand a considerable computational effort. Therefore, finding the competition index that provides comparable accuracy of estimation of the number of resources allocated among trees in complex forest stands will allow developing more efficient ecological models, especially for planning in uneven-aged forestry, where the competition among trees and possible changes due to cuttings play the most crucial role in growth and survival of trees.

The purpose of the study was to analyze how the capability of competition indices to take into account the relative spatial locations of trees affects their performance in reproducing the interactions between trees. We compared the performance of three competition indices with outputs of spatially explicit mechanistic models of above- and belowground competition, as well as with the empirical data. To apply the indices to multispecies forest stands, the species-specific parameters were estimated based on the independent dataset for Scots pine (Pinus sylvestris L.), Norway spruce (Picea abies (L.) H. Karst.), birch (the same parameters were set for both silver birch Betula pendula Roth and downy birch Betula pubescens Ehrh.), and European aspen (Populus tremula L.), hereafter referred to as pine, spruce, birch, and aspen, respectively.

\section{Materials and Methods}

\subsection{Description of Competition Indices}

We took for the comparison the indices that utilize standard data of forest surveys (e.g., stem height and/or diameter at breast height (DBH)) and have species-specific coefficients.

The Hegyi index [13] $\mathrm{CIH}_{i}$ estimates competition on the basis of the size of focal tree $i$, that of neighbor tree $j$, and also the distance between them as follows:

$$
C I H_{i}=\sum_{j \neq i}^{n} \frac{D B H_{j}}{D B H_{i} \cdot r_{i j}}
$$

where $D B H_{i}$ is the stem diameter at breast height of focal tree $i(\mathrm{~cm}), D B H_{j}$ is the stem diameter at breast height of neighbor tree $j(\mathrm{~cm}), r_{i j}$ is the distance between focal tree $i$ and neighbor tree $j(\mathrm{~m})$, and $n$ is the number of neighbors of the focal tree $i$.

The selection of neighbor trees for the calculation of the index is based on the calculation of angles $\gamma_{i}$ and $\gamma_{j}$. Angle $\gamma_{i}$ is calculated as follows:

$$
\gamma_{i}=2 \cdot \arctan \left(\frac{D B H_{i}}{A}\right)
$$

where $A$ is the species-specific parameter defining the search radius (m) (Table 1$)$, and $D B H_{i}$ is the stem diameter $(\mathrm{cm})$ at breast height for focal tree $i$.

Table 1. Species-specific coefficients used for the calculation of competition indices.

\begin{tabular}{ccccccccc}
\hline Species & $\boldsymbol{A}$ & $\gamma_{\boldsymbol{l}}$ & $\boldsymbol{x}$ & $\boldsymbol{y}$ & $\boldsymbol{z}$ & $\boldsymbol{W}$ & $\boldsymbol{\alpha}$ & $\boldsymbol{\beta}$ \\
\hline pine & 4.5 & 5.0 & 5 & 4 & 3 & 18 & 3.64 & 0.95 \\
spruce & 3.0 & 16.0 & 4 & 1 & 17 & 15 & 4.07 & 0.29 \\
birch & 5.5 & 11.5 & 3 & 5 & 7 & 19 & 3.82 & 1.22 \\
aspen & 5.0 & 10.9 & 3 & 5 & 5 & 21 & 3.78 & 1.25 \\
\hline
\end{tabular}


Angle $\gamma_{i}$ is to be compared with angle $\gamma_{j}$, which is calculated as follows:

$$
\gamma_{j}=2 \cdot \arctan \left(\frac{D B H_{j}}{r_{i j}}\right)
$$

where $D B H_{j}$ is stem diameter $(\mathrm{cm})$ at breast height for neighbor tree $j$, and $r_{i j}$ is the distance between focal tree $i$ and certain neighbor tree $j(\mathrm{~m})$. All trees meeting the conditions that $\gamma_{i} \leq \gamma_{j}$ and $r_{i j} \leq A$ are considered as neighbor trees for the given focal tree $i$.

Here, we reintroduce the angular competition index $C I A_{i}$, which was initially suggested in [14]. The specific feature of this index is based on the angle sectors formed by tangent lines from the location of the focal tree to the edges of the influence zones of its neighbor trees. The neighbor selection criterion is similar to those for the Hegyi index (Equation (2)), but the angle $\gamma_{i}$ is compared with the certain species-specific threshold value of $\gamma_{l}$ (Table 1).

After the selection of competing trees for each neighbor tree $j$, the radius $R_{j}$ of its influence zone on the focal tree $i$ is calculated.

$$
R_{j}=\left(\frac{A r_{i}}{c}\right)^{\frac{1}{x}} \cdot\left(\frac{D B H_{j}}{D B H_{i}}\right)^{y},
$$

where $x, y, c$ are scaling factors, $D B H_{i}$ and $D B H_{j}$ are the stem diameters at breast height of the focal and neighbor trees, respectively, and the index of crown projections overlap $A r_{i}$ is calculated as follows [15]:

$$
A r_{i}=\frac{\left(\sum_{j=1}^{n} a_{i j}-\sum_{f=1}^{k-1} a_{i f}+\sum_{g=1}^{m} a_{i g}\right)+C A_{i}}{C A_{i}},
$$

where $n$ is the number of trees that have overlapping crown projections (represented as circles) with the crown projection of the focal tree $i, k$ is the number of trees for which the crown projections completely overlap with the crown projection of the focal tree $i, m$ is the number of trees for which the crown projections are inside the crown projection of the focal tree $i$, and $C A_{i}$ is the theoretical crown projection area of tree $i$ for the case of growth in open space, which is calculated as follows:

$$
C A_{i}=\pi \cdot\left(\frac{W \cdot D B H_{i}}{2}\right)^{2}
$$

where $W$ is the species-specific ratio of crown projection diameter to the stem diameter at breast height of the tree, and $D B H_{i}$ is the stem diameter at breast height of the focal tree. The crown projection radius $C R_{i}$ is calculated in a similar way.

The area of overlapping crowns projections of trees $i$ and $j, a_{i j}$, is calculated as follows:

$$
a_{i j}=\frac{C R_{i}^{2} \cdot\left(F_{i}-\sin \left(F_{i}\right)\right)}{2}+\frac{C R_{j}^{2} \cdot\left(F_{j}-\sin \left(F_{j}\right)\right)}{2}
$$

where

$$
\begin{aligned}
& F_{i}=2 \cdot \arccos \left(\frac{C R_{i}^{2}-C R_{j}^{2}+r_{i j}^{2}}{2 \cdot C R_{i} \cdot r_{i j}}\right), \\
& F_{j}=2 \cdot \arccos \left(\frac{C R_{j}^{2}-C R_{i}^{2}+r_{i j}^{2}}{2 \cdot C R_{j} \cdot r_{i j}}\right),
\end{aligned}
$$

where $C R_{i}, C R_{j}$ are the radii of crown projections of the focal and neighbor trees, respectively, and $r_{i j}$ is a distance between the trees.

Further, the sectors were determined by tangent lines from the focal tree location to the edges of the influence zones of each neighbor tree $R_{j}$. The resulting competition index is the arithmetic mean of two components, the first of which represents the belowground 
competition, and the second one represents the aboveground competition (assuming the equal influence of both kinds of competition on the growth of trees). The first component is calculated as the sum of angular sizes of sectors, while for the calculation of the second component the overlapping sectors are excluded (i.e., overlapping areas of sectors are accounted for only once). To account for the heterogeneity of the incoming photosynthetically active radiation (PAR) from different directions, an additional weighting factor was introduced. For azimuth $0^{\circ}$ (geographic north) this factor was set at 0.5 , for azimuth $180^{\circ}$ (south), it was set at 1.5 , for azimuths $90^{\circ}$ and $270^{\circ}$ (east and west, respectively), it was set at 1.0, and for intermediate directions, the value of this coefficient is interpolated between the closest base values with $0.1^{\circ}$ discretization. The values of the scaling factor were estimated from the parameterization of the spatially explicit model of aboveground competition [12]. The schematic representation of the calculation of the angular index is provided in Figure 1.

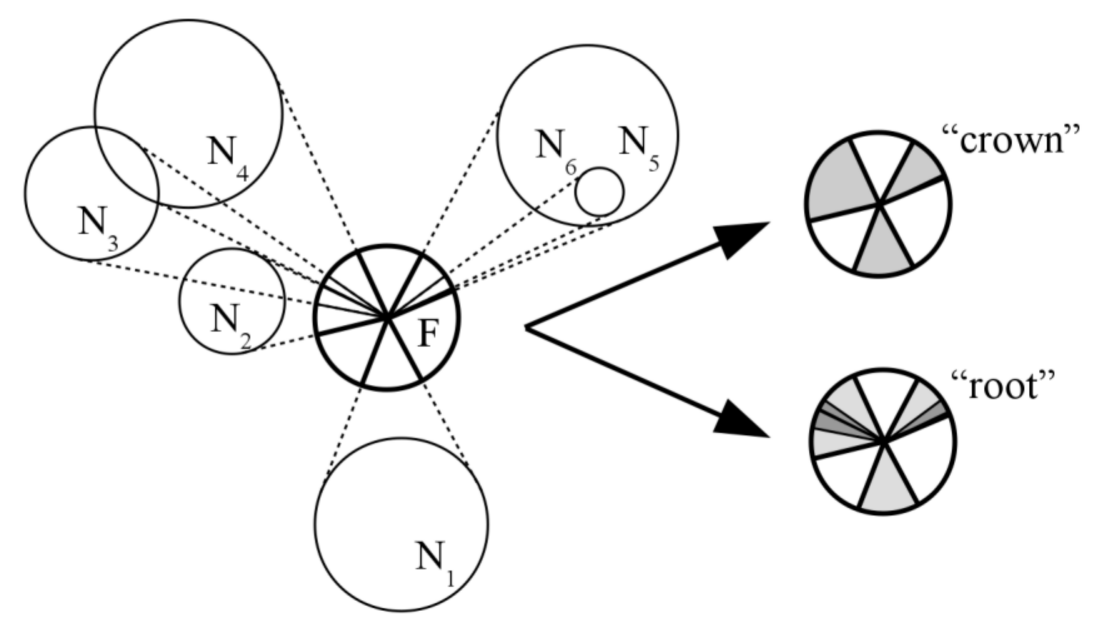

Figure 1. The schematic representation of the calculation of the angular competition index. Influence zones of neighbor trees $\mathrm{N}_{1}-\mathrm{N}_{6}$ generate sectors of the influence zone of the focal tree F. Combining these sectors with and without taking into account the overlapped areas produces the components of the competition index related to the root and crown competition, respectively. The intensity of gray filling denotes the competition strength.

By construction, the angular completion index takes into account the relative locations of neighbor trees. This property, which can be attributed to spatial asymmetry, is seldom taken into account in many of the known competition indices.

The third competition measure in the comparison study is based on the competition kernels $C_{I K}$ which determine the competitive load not at locations of trees specifically but rather at each point of a plot area, and thus, they are the alternative for competition indices [16]. Generally, they can be represented as function $p_{i}(z)$, which describes the local influence of a certain tree $i$ on its environment at a point $z$ [17].

$$
p_{i}(z)=\frac{D B H_{i}^{\alpha}}{1+\left(\frac{r_{i}(z)}{\beta}\right)^{2}},
$$

where $D B H_{i}$ is stem diameter at breast height, $r_{i}(z)$ is the distance between the focal tree and given point, $\alpha$ and $\beta$ are species-specific coefficients (Table 1).

To calculate the competitive pressure on each tree in a forest stand, the influences of all neighbor trees in the point corresponding to the location of the focal tree were summed as follows:

$$
C I K_{i}=\sum_{j \neq i} p_{j}(i)
$$


where $p_{j}(i)$ denotes the influence of the neighbor tree $j$ on the focal tree $i$.

In contrast to competition indices, which describe the influence of neighbor trees only in the point corresponding to the location of the focal tree [18], the competition kernels form a competition field. This, in theory, could be useful for the assessment of the influence of trees on the undergrowth and ground-layer vegetation.

Since the competition effect is also dependent on the size of the focal tree (expressed through its stem diameter at breast height, $D B H_{i}$ ), the competition index was transformed as follows:

$$
C I K_{i}=\frac{C I K_{i}}{D B H_{i}+C I K_{i}} .
$$

According to [18], such transformation increases the biological plausibility and improves the model behavior due to the nonlinear relationship between the size of the focal tree and the weakening of the competitive pressure.

The calculation of all competition indices was carried out in statistical programming environment $R$ v. 3.1.1 [19]. The values of coefficient $W$ (Table 1) were estimated from the experimental data on the crown size on the sampling plots [20,21]. The values of other coefficients were estimated with the least-squares method using the data from the yield tables [22,23]—namely, the parameters of the equations for competition indices were estimated by fitting to the normalized values of annual volume increment of pure stands reported in these tables.

\subsection{Brief Description of Spatially Explicit Mechanistic Models of Competition}

Two simulation models applied in the current study are mechanistic, individual based, and spatially explicit. Each tree has an explicitly defined location on the simulation plot, which is divided into square cells. The multi-layered model of belowground competition for available nitrogen in soil [11] describes the spatial distribution of belowground biomass of trees. The area of the nutrition zone is calculated based on the mean distance of horizontal spreading of roots, which, in turn, depends on DBH and species-specific coefficients. The preferability of occupation of a certain cell is dependent on the amount of available nitrogen in this cell, the distance between cell and stem base, and the biomass of fine roots of other competing trees in the given cell. The vertical distribution of biomass of roots is described by function with species-specific parameters. The intensity of nitrogen uptake is dependent on species-specific features, the age of a tree, and the biomass of its fine roots in a given cell. The main output from the model is the amount of nitrogen consumed by each tree.

The model of aboveground competition allows calculating the amount of PAR captured by each tree. An advanced property of the model is its capability to simulate the crown asymmetry arising as an adaptive response of a tree on the competitive pressure from neighbor trees [12]. The crown shape is species specific, while crown dimensions are dependent on the height and DBH of the tree, and the local stand density. The crown of a tree is approximated by 3-dimensional cells, and crowns of several trees can be presented in the same cell. To take into account the influence of neighbor trees, the Voronoi partitioning is applied to the simulation plot. Depending on the available space, determined by Voronoi polygons, the crown width in different directions is modified, thus allowing the simulation of asymmetry resulted from the inter-tree competition for light. The model also simulates the distribution of biomass inside the crown using species-specific coefficients. At the final stage, the model calculates the amount of PAR intercepted by the given tree with a simplified ray-tracing technique [12]. The amount of intercepted PAR is affected by leaf area index (LAI) in a given cell, while the transmitted part of PAR is passed to lower canopy layers [24]. The main output from the model is the amount of PAR absorbed by each tree.

These two models have species-specific parameters describing the distribution of roots in soil and foliage inside the crown, and also peculiarities of nitrogen uptake and light interception. These features allow simulation of intra- and inter-specific competition and represent the plasticity of root systems and crowns as an adaptation mechanism to the competition for resources. Thus, the above-described models represent life strategies 
of different tree species and take into account the spatial heterogeneity of the environment, which allows them to simulate more accurately the competition and tree growth in heterogeneous forest stands. The models were implemented using the Object Pascal programming language with Lazarus v. 1.2.4 Integrated Development Environment (Free Pascal Compiler v. 2.6.4) under Debian GNU/Linux 8.

\subsection{Design of the Simulation Experiment}

We used a set of simulation scenarios to compare the competition indices by outputs of spatially explicit models. All simulations were carried out on a simulation plot of $50 \times$ $50 \mathrm{~m}$ divided into square cells of $0.5 \times 0.5 \mathrm{~m}$. The plot was "wrapped around the torus" to eliminate the edge effect [25].

The set of scenarios included a simulation of stands of different development stages and spatial structures (Table 2). Simulated stands consisted of spruce, pine, birch, and aspen in different combinations. Three types of spatial structure were simulated: regular (location of trees on a regular grid), random, and location of trees in several dense clusters according to Neyman-Scott algorithm [26]).

Table 2. Initial parameters ( \pm standard deviation) of stands used for simulations.

\begin{tabular}{|c|c|c|c|c|}
\hline Stand Type & Age, Years & Density, ha ${ }^{-1}$ & Height, m & $\mathrm{DBH}, \mathrm{cm}$ \\
\hline Young & 5 & 10,000 & $1.8 \pm 0.45$ & $1 \pm 0.25$ \\
\hline Pole & 30 & 1600 & $5 \pm 1.25$ & $5 \pm 1.25$ \\
\hline Mature & 70 & 448 & $22 \pm 3.3$ & $25 \pm 3.75$ \\
\hline Canopy & 70 & 224 & $22 \pm 3.3$ & $25 \pm 3.75$ \\
\hline Undergrowth & 30 & 800 & $5 \pm 1.25$ & $5 \pm 1.25$ \\
\hline Uneven aged & $20-230$ & 768 & $1.9-19.2$ & $4.1-38.9$ \\
\hline
\end{tabular}

To standardize calculated values of all three competition indices ( $\mathrm{CIH}, \mathrm{CIA}$, and $\mathrm{CIK})$, they were transformed as follows:

$$
C I_{i}^{\text {trans }}=1-\frac{C I_{i}}{\max (C I)},
$$

where $C I_{i}$ denotes any type of competition index for the $i$-th tree.

By this transformation, we obtain a new set of values that fits the range $[0,1]$ where the least value corresponds now to the tree received the minimal amount of resource (i.e., the most suppressed tree in a stand), and the maximal value corresponds to the least suppressed tree. To estimate the sensitivity and make the conclusions justified, the Monte Carlo runs with 1000 repetitions and 10\% variation of parameters were used.

The amount of available nitrogen and absorbed PAR by each tree were calculated with spatially explicit mechanistic models of below- [11] and aboveground competition [12], respectively. The obtained values were similarly normalized to fit the range $[0,1]$.

$$
R E S_{i}^{\text {trans }}=\frac{R E S_{i}}{\max (R E S)},
$$

where $R E S_{i}$ is the number of resources obtained by a certain tree. For each tree, the arithmetic mean between normalized values of resources obtained from above- and belowground competition was calculated.

To estimate the agreement between outputs from the detailed mechanistic models of competition and the simplified competition indices, we used the Pearson linear correlation coefficient $r$. Calculations were carried out in statistical programming environment R v. 3.1.1 [19]. 


\subsection{Description of Experimental Data Used for Comparison of the Competition Indices}

The comparison between competition indices was carried out also by the experimental data on the growth of individual trees in mapped stands. The experimental dataset on peatland forests drained in 1963 was obtained from the Heinävesi experimental site (Heinävesi municipality) in eastern Finland $\left(62.45^{\circ} \mathrm{N}, 29.10^{\circ} \mathrm{E}\right.$, and $114 \mathrm{~m}$ a.s.l). The long-term (1981-2010) mean annual precipitation is $575 \mathrm{~mm}$, and the temperature sum of the growing season is $1248 \mathrm{dd}$. (threshold value $+5^{\circ} \mathrm{C}$ ). The area represents predominately Norway spruce forest with an admixture of Scots pine and downy birch classified as Vaccinium myrtillus type drained peatland [27]. The site was divided into 12 subplots representing different thinning treatments conducted in 1994, with a total area of approximately 2.6 ha. Consequent inventories were carried out in 1994, 1998, 2003, and 2008, measuring the DBH of each tree. Excluding trees that did not survive until the last inventory, the total number of measured trees comprised 920 individual trees. The DBH ranged between 4.6 and $46.9 \mathrm{~cm}$, with mean value increased from $17.0 \mathrm{~cm}$ in 1994 to $21.5 \mathrm{~cm}$ in 2008. The distribution was unimodal and almost symmetric (slightly left skewed). Due to the nonsquare shape of plots, traditional methods of elimination of the edge effect were inapplicable. Instead, a buffer area of $6 \mathrm{~m}$ on edge of each plot was chosen, and trees in this zone were excluded from the analysis. Therefore, the total number of trees accounted for in the analysis comprised 277.

To estimate the performance of different competition indices and estimate the relationship between 5-year diameter increment and values of different competition indices, we applied the Spearman rank correlation coefficient, as suggested in [28]. The 5-year diameter increment for the first period (1994-1998) was calculated by multiplying the original value by $(5 / 4)$.

\section{Results and Discussion}

The correlation analysis between outputs from detailed mechanistic models of competition and competition indices (Figure 2) showed that the angular competition index represents the distribution of common resources among individual trees with the best similarity to models of competition, among three considered indices. The mean value of correlation coefficient $(r)$ was 0.728 , and for $70 \%$ of stands, the value of $r$ for the angular competition index was the highest among all three considered indices. For this index, the cases with $r<0.5$ were absent. The Hegyi index also showed satisfactory results: the mean value of $r$ was 0.612 , and for $20 \%$ of cases $r$ was less than 0.5 . For $30 \%$ of cases, the value of $r$ for this index was the highest among all three considered indices. The competition kernels showed a lower correlation, with the mean value of $r$ at 0.556 , and $r<0.5$ in $28 \%$ of cases. Better performance of angular-based indices was also shown previously [29].

The competition indices more efficiently represented the competition in young and pole, rather than in mature stands. The considered indices showed the best agreement with detailed models of competition in the case of random and regular placement of trees. Most likely, such results can be explained by an underestimation of the adaptation of trees to competitive pressure from neighbors through asymmetric development of crowns and root systems $[4,20,30-32]$.

The correlation analysis between different indices showed that the best similarity was observed between the Hegyi index and angular index, where the value of $r$ ranged between 0.692 and 0.939 (the mean value comprised 0.845). The range of $r$ between the Hegyi index and competition kernels across all sample stands ranged between 0.481 and 0.928 , with a mean value at 0.768 . The comparison between competition kernels and angular index showed lower values of $r$ (minimum at 0.196 , mean at 0.590 , and maximum at 0.777 ). In general, the correlation between values of different indices decreased with the age of the stand. 

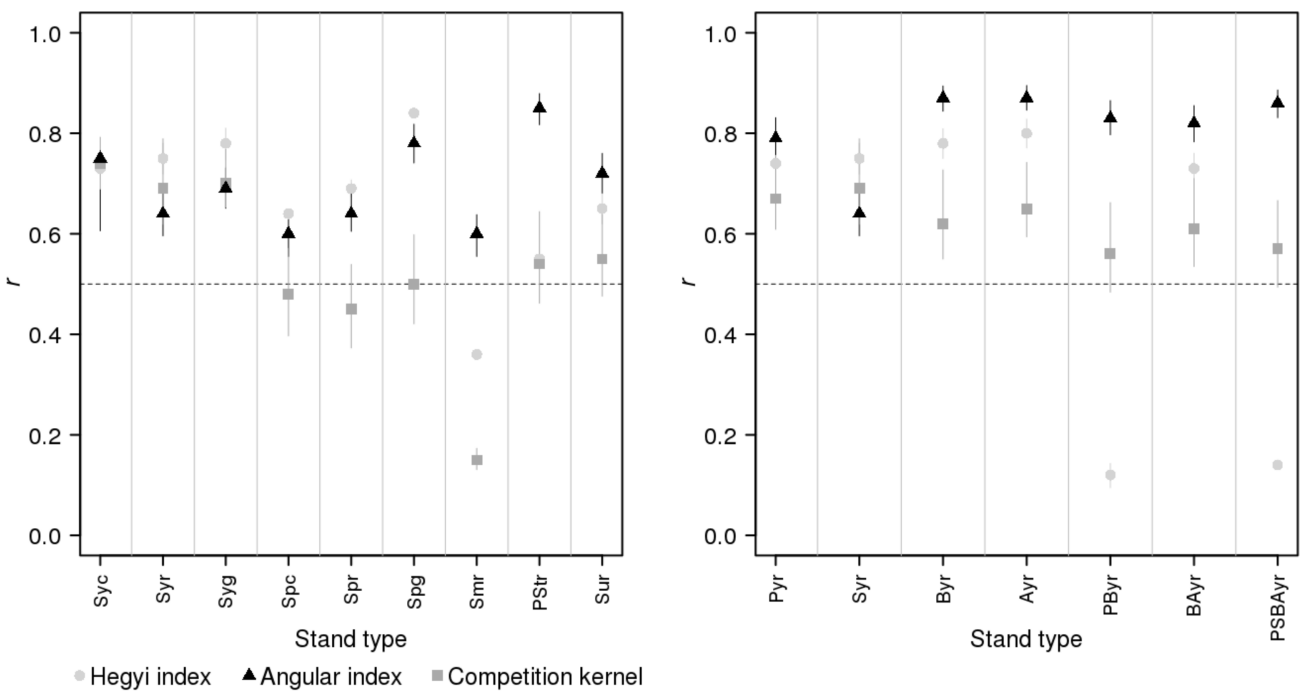

Figure 2. Pearson linear correlation $(r)$ between outputs from three competition indices $\left(C I_{i}\right)$ and outputs from mechanistic spatially explicit models $\left(R E S_{i}\right)$. Dashed horizontal line denotes $r=0.5$. Stand type codes are the following: uppercase letters denote species ( $\mathrm{P}$ - pine, $\mathrm{S}$-spruce, $\mathrm{B}$-birch, A-aspen), first lowercase letter denotes stand age ( $\mathrm{y}$-young, $\mathrm{p}$ - pole, $\mathrm{m}$-mature, $\mathrm{t}$ - two layered, $\mathrm{u}$-uneven aged), and second lowercase letter denotes spatial structure of stand ( $\mathrm{r}$-random location of trees, c-clustered location, g-location on a regular grid). The standard deviation obtained with the Monte Carlo runs is also shown.

Figure 3 represents the relationship between different competition indices for some sample stands with more details. The general trend is the increase of difference between indices with the stand age, thus reflecting the increased role of spatial heterogeneity. The relationship between the Hegyi index and angular index is linear, while it is nonlinear for other cases.

The correlation between 5-year DBH increment and values of competition indices (Table 3) generally showed better performance of the angular index and the similar performance of Hegyi index and competition kernels. Lower correspondence between competition indices and measured diameter increment, in comparison to the correspondence between competition indices and outputs of competition models, can also originate from our assumption on the equal contribution of above- and belowground competition, while in real stands, these types of competition may differ in their importance for the performance of individual trees.

Table 3. The values of Spearman correlation coefficients between the 5-year tree diameter increment and three different competition indices for 12 sample subplots of the Heinävesi experimental site. The values $>0.5$ in absolute magnitude are shown in bold.

\begin{tabular}{cccc}
\hline Subplot & Hegyi Index & Angular Index & Competition Kernel \\
\hline 1 & $\mathbf{0 . 5 4 4}$ & $\mathbf{0 . 6 5 7}$ & 0.493 \\
2 & $\mathbf{0 . 5 9 0}$ & $\mathbf{0 . 6 6 2}$ & $\mathbf{0 . 5 1 5}$ \\
3 & $\mathbf{0 . 5 6 7}$ & $\mathbf{0 . 6 6 9}$ & $\mathbf{0 . 5 0 9}$ \\
4 & $\mathbf{0 . 5 5 6}$ & $\mathbf{0 . 6 8 0}$ & 0.499 \\
5 & $\mathbf{0 . 5 4 5}$ & $\mathbf{0 . 6 7 7}$ & $\mathbf{0 . 5 1 6}$ \\
6 & $\mathbf{0 . 5 6 7}$ & $\mathbf{0 . 6 7 1}$ & $\mathbf{0 . 5 2 0}$ \\
7 & $\mathbf{0 . 5 7 1}$ & $\mathbf{0 . 6 6 3}$ & $\mathbf{0 . 5 1 6}$ \\
8 & $\mathbf{0 . 5 5 9}$ & $\mathbf{0 . 6 7 2}$ & $\mathbf{0 . 5 1 5}$ \\
9 & $\mathbf{0 . 5 8 4}$ & $\mathbf{0 . 6 6 5}$ & $\mathbf{0 . 5 0 7}$ \\
10 & $\mathbf{0 . 5 3 9}$ & $\mathbf{0 . 6 5 2}$ & 0.489 \\
11 & $\mathbf{0 . 5 9 0}$ & $\mathbf{0 . 6 7 9}$ & $\mathbf{0 . 5 2 0}$ \\
12 & $\mathbf{0 . 5 4 8}$ & $\mathbf{0 . 6 7 4}$ & $\mathbf{0 . 5 0 9}$ \\
\hline
\end{tabular}



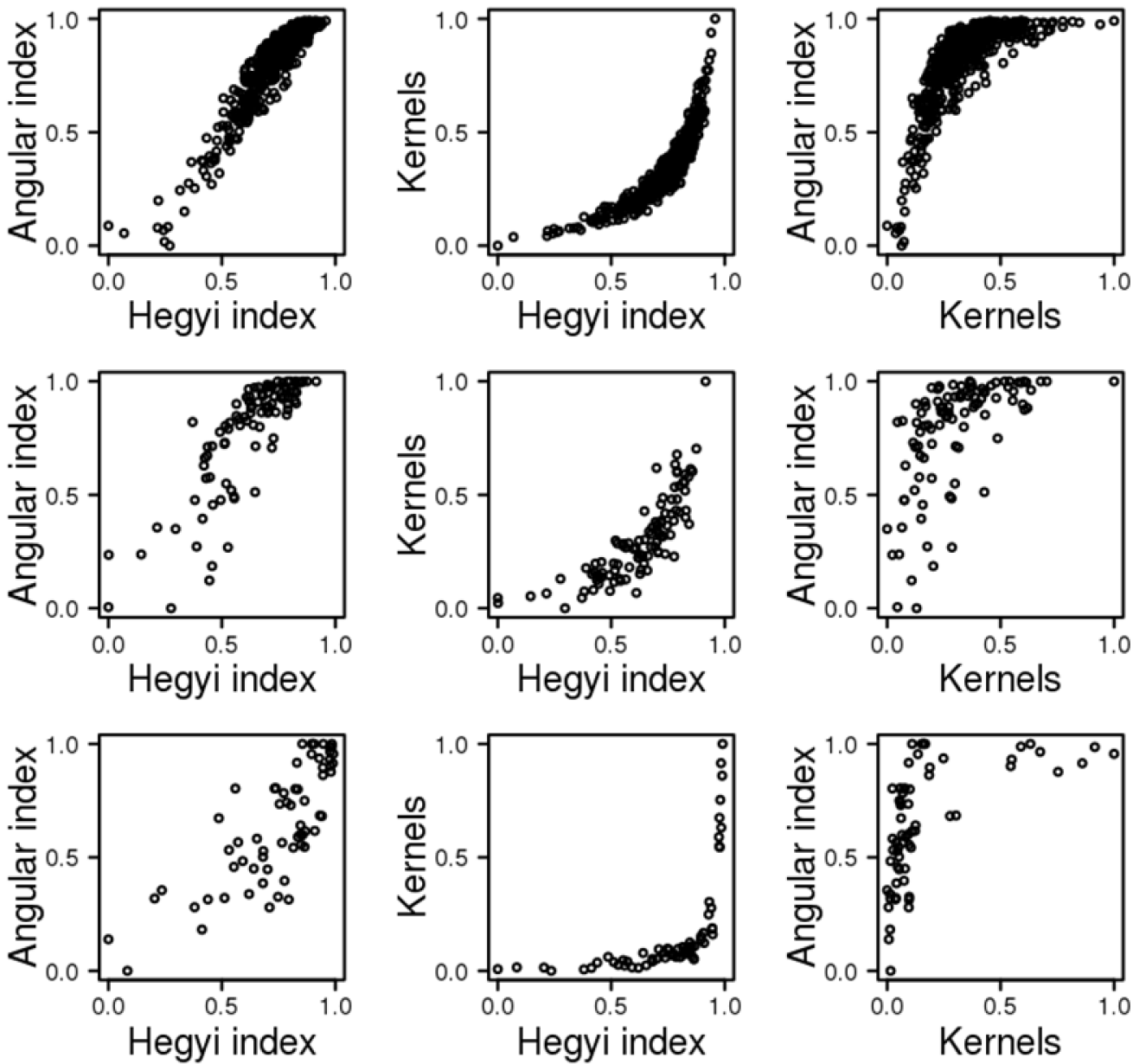

Figure 3. The normalized values of different competition indices for some sample stands, plotted against each other. The upper row represents the young pine stand with random placement of trees, the middle row represents the pole stand with equal portions of birch and aspen with a clustered placement, and the bottom row represents the mature pine stand with spruce undergrowth under the canopy.

\section{Conclusions}

The comparison with outputs from spatially explicit mechanistic models of aboveand belowground competition showed the fundamental importance of taking into account the spatial structure of stands and, particularly, the relative positions of individual trees when calculating the competition between them. Such importance is supported by the best results shown by the angular index.

The angular competition index is relatively simple and can be calculated from the basic and easily measured characteristics of trees, such as stem diameter or height, and in the case if their locations are known. Moreover, it allows for estimating the competition based on the differences between above- and belowground competition, while most of the competition indices were designed and parameterized based on aboveground competition only.

However, comparison with measured data on the growth of individual trees showed that any competition index could be considered only as a simplified representation of competition between trees for resources because it is unable to take into account all possible causes that might affect the development of each tree. Nevertheless, due to the simplicity of competition indices, they can be useful in cases where the detailed mechanistic models are inapplicable. For example, the models based on competition indices can be applied for individual-based simulation of stand development at large scales with low computational demands. The competition indices, due to their simplicity, can be also used for the analysis 
of how the parameters of trees and the spatial structure of stand affect the interaction between trees.

The tree species that were chosen for the analysis are typical for the European boreal forests. The open question is if the study outputs are applicable for other forest zones, e.g., for temperate or tropical forests, where the limiting factors are different. However, we would expect that the general findings in spite of the different representation of interactions between trees of various life strategies will be valid irrespective of forest type and tree species and will be determined by the spatial structure of the stand. Another possible limitation is that our approach was not tested in relation to the changes in forest ecosystems that resulted from either natural development or disturbances, including climate change or forest management activity. Since the indices are calculated on the basis of the relative positions and sizes of individual trees, any changes related to the stand dynamics will be represented with the values of indices. However, in the case of environmental changes affecting ecosystem parameters not accounted for in the indices, the approach would require additional testing and additional data.

Author Contributions: Conceptualization, V.S. and P.G.; methodology, V.S. and P.G.; software, V.S.; validation, V.S.; formal analysis, V.S.; investigation, V.S. and P.G.; resources, H.H.; data curation, H.H.; writing - original draft preparation, V.S.; writing - review and editing, P.G. and H.H.; visualization, V.S.; supervision, P.G.; project administration, P.G.; funding acquisition, P.G. and H.H. All authors have read and agreed to the published version of the manuscript.

Funding: The study was supported by the Russian Science Foundation, project \#18-14-00362 (Vladimir Shanin, Pavel Grabarnik-constructing and testing the indices, APC payment), and by the Academy of Finland, projects \#322972, \#312912, and \#336570 (Hannu Hökkä-collecting and processing the experimental data for validation).

Institutional Review Board Statement: Not applicable.

Informed Consent Statement: Not applicable.

Data Availability Statement: The data are contained within the article.

Acknowledgments: Not applicable.

Conflicts of Interest: The authors declare no conflict of interest.

\section{References}

1. Uria-Diez, J.; Pommerening, A. Crown plasticity in Scots pine (Pinus sylvestris L.) as a strategy of adaptation to competition and environmental factors. Ecol. Model. 2017, 356, 117-126. [CrossRef]

2. Cabal, C.; Martínez-García, R.; Valladares, F. The ecology of plant interactions: A giant with feet of clay. Preprints 2020, unpublished work.

3. Trinder, C.J.; Brooker, R.W.; Davidson, H.; Robinson, D. Directly quantifying multiple interacting influences on plant competition. Plant Cell Environ. 2021, 44, 1268-1277. [CrossRef] [PubMed]

4. Pretzsch, H. Canopy space filling and tree crown morphology in mixed-species stands. For. Ecol. Manag. 2014, 327, 251-264. [CrossRef]

5. Perttunen, J. The LIGNUM Functional-Structural Tree Model [Dissertation]; Systems Analysis Laboratory, Helsinki University of Technology: Helsinki, Finland, 2009; ISBN 978-951-22-9709-2.

6. Olchev, A.; Radler, K.; Sogachev, A.; Panferov, O.; Gravenhorst, G. Application of a three-dimensional model for assessing effects of small clear-cuttings on radiation and soil temperature. Ecol. Model. 2009, 220, 3046-3056. [CrossRef]

7. Mao, Z.; Saint-André, L.; Bourrier, F.; Stokes, A.; Cordonnier, T. Modelling and predicting the spatial distribution of tree root density in heterogeneous forest ecosystems. Ann. Bot. 2015, 116, 261-277. [CrossRef]

8. Daniels, R.F.; Burkhart, H.E.; Clason, T.R. A comparison of competition measures for predicting growth of loblolly pine trees. Can. J. For. Res. 1986, 16, 1230-1237. [CrossRef]

9. Rouvinen, S.; Kuuluvainen, T. Structure and asymmetry of tree crowns in relation to local competition in a natural mature Scot pine forest. Can. J. For. Res. 1997, 27, 890-902. [CrossRef]

10. Corral Rivas, J.J.; Álvarez González, J.G.; Aguirre, O.; Hernández, F.J. The effect of competition on individual tree basal area growth in mature stands of Pinus cooperi Blanco in Durango (Mexico). Eur. J. For. Res. 2005, 124, 133-142. [CrossRef] 
11. Shanin, V.; Mäkipää, R.; Shashkov, M.; Ivanova, N.; Shestibratov, K.; Moskalenko, S.; Rocheva, L.; Grabarnik, P.; Bobkova, K.; Manov, A.; et al. New procedure for the simulation of belowground competition can improve the performance of forest simulation models. Eur. J. For. Res. 2015, 134, 1055-1074. [CrossRef]

12. Shanin, V.N.; Grabarnik, P.Y.; Shashkov, M.P.; Ivanova, N.V.; Bykhovets, S.S.; Frolov, P.V.; Stamenov, M.N. Crown asymmetry and niche segregation as an adaptation of trees to competition for light: Conclusions from simulation experiments in mixed boreal stands. MCFNS 2020, 12, 26-49. [CrossRef]

13. Hegyi, F. A simulation model for managing jack-pine stands. In Growth Models for Tree and Stand Simulation. Proceedings IUFRO Meeting S4.01.04; Fries, J., Ed.; Royal College of Forestry: Stockholm, Sweden, 1974; pp. 74-90.

14. Sizov, I.; Grabarnik, P. The comparison of competition indices with simulation model of the light regime of forest canopy [Sravnenie indeksov konkurentsii s pomoshch'yu imitatsionnoi modeli svetovogo rezhima drevostoya]. In Principles and Ways to the Biodiversity Conservation: Proceedings of III All-Russian Scientific Conference; Zhukova, L., Ed.; Mari State University: Yoshkar-Ola, Russia, 2008; pp. 488-489.

15. Arney, J.D. Tables for Quantifying Competitive Stress on Individual Trees; Inf. Rep. BC-X-7; Canadian Forestry Service, Pacific Forest Research Center: Victoria, BC, Canada, 1973.

16. Schneider, M.K.; Law, R.; Illian, J.B. Quantification of neighborhood-dependent plant growth by Bayesian hierarchical modelling. J. Ecol. 2006, 94, 310-321. [CrossRef]

17. Pommerening, A.; LeMay, V.; Stoyan, D. Model-based analysis of the influence of ecological processes on forest point pattern formation-A case study. Ecol. Model. 2011, 222, 666-678. [CrossRef]

18. Pommerening, A.; Maleki, K. Differences between competition kernels and traditional size-ratio based competition indices used in forest ecology. For. Ecol. Manag. 2014, 331, 135-143. [CrossRef]

19. R Core Team. R: A Language and Environment for Statistical Computing. Available online: http:/ / www.R-project.org/ (accessed on 26 August 2021).

20. Shanin, V.N.; Shashkov, M.P.; Ivanova, N.V.; Grabarnik, P.Y. The effect of aboveground competition on spatial structure and crown shape of the dominating canopy species of forest stands of European Russia [Vliyanie konkurentsii v pologe lesa na prostranstvennuyu strukturu drevostoev i formu kron dominantov drevesnogo yarusa na primere lesov evropeiskoi chasti Rossii]. RJEE 2016, 1. (In Russian) [CrossRef]

21. Shashkov, M.; Ivanova, N.; Shanin, V.; Grabarnik, P. Ground surveys versus UAV photography: The comparison of two tree crown mapping techniques. In Information Technologies in the Research of Biodiversity; Springer Proceedings in Earth and Environmental Sciences; Bychkov, I., Voronin, V., Eds.; Springer: Cham, Switzerland, 2019; pp. 48-56. [CrossRef]

22. Shvidenko, A.Z.; Schepaschenko, D.G.; Nilsson, S.; Buluy, Y.I. Tables and Models of Growth and Productivity of Forests of Major Forest Forming Species of Northern Eurasia (Standard and Reference Materials), Second Edition, Supplemented; Federal Agency of Forest Management, International Institute For Applied Systems Analysis: Moscow, Russia, 2008.

23. Usoltsev, V.A. Biological Productivity of Forest-Forming Species in Eurasia's Climatic Gradients (as Related to Supporting Decision-Making Processes in Forest Management) [Biologicheskaya Produktivnost' Lesoobrazuyushchikh Porod v Klimaticheskikh Gradientakh Evrazii (k Menedzhmentu Biosfernykh Funktsiy Lesov)]; Ural State Forest Engineering University: Ekaterinburg, Russia, 2016. (In Russian)

24. Collalti, A.; Perugini, L.; Santini, M.; Chiti, T.; Nolèc, A.; Matteucci, G.; Valentini, R. A process-based model to simulate growth in forests with complex structure: Evaluation and use of 3D-CMCC Forest Ecosystem Modeling a deciduous forest in Central Italy. Ecol. Model. 2014, 272, 362-378. [CrossRef]

25. Haefner, J.W.; Poole, G.C.; Dunn, P.V.; Decker, R.T. Edge effects in computer models of spatial competition. Ecol. Model. 1991, 56, 221-244. [CrossRef]

26. Illian, J.; Penttinen, A.; Stoyan, H.; Stoyan, D. Statistical Analysis and Modelling of Spatial Point Patterns; John Wiley \& Sons: New York, NY, USA, 2008.

27. Vasander, H.; Laine, J. Site type classification on drained peatlands. In Finland_Fenland: Research and Sustainable Utilisation of Mires and Peat; Korhonen, R., Korpela, L., Sarkkola, S., Eds.; Finnish Peatland Society, Maahenki Ltd.: Helsinki, Finland, 2008; pp. 146-151, ISBN 978-952-5652-47-5.

28. Pedersen, R.Ø.; Næsset, E.; Gobakken, T.; Bollandsås, O.M. On the evaluation of competition indices-The problem of overlapping samples. For. Ecol. Manag. 2013, 310, 120-133. [CrossRef]

29. Maleki, K.; Kiviste, A.; Korjus, H. Analysis of individual tree competition effect on diameter growth of silver birch in Estonia. For. Syst. 2015, 24, e23. [CrossRef]

30. Shanin, V.N.; Rocheva, L.K.; Shashkov, M.P.; Ivanova, N.V.; Moskalenko, S.V.; Burnasheva, E.R. Spatial distribution features of the root biomass of some tree species (Picea abies, Pinus sylvestris, Betula sp.). Biol. Bull. 2015, 42, 260-268. [CrossRef]

31. Pretzsch, H.; Schütze, G. Effect of tree species mixing on the size structure, density, and yield of forest stands. Eur. J. For. Res. 2016, 135, 1-22. [CrossRef]

32. Morin, X.; Fahse, L.; Scherer-Lorenzen, M.; Bugmann, H. Tree species richness promotes productivity in temperate forests through strong complementarity between species. Ecol. Lett. 2011, 14, 1211-1219. [CrossRef] 